\title{
Halogenated cyclic peptides isolated from the sponge Corticium sp.
}

Damian W. Laird, ${ }^{\dagger}$ Daniel V. LaBarbera, ${ }^{\dagger}$ Xidong Feng, ${ }^{\ddagger}$ Tim S. Bugni,${ }^{\dagger}$ Mary Kay Harper ${ }^{\dagger}$ and Chris M. Ireland ${ }^{\dagger *}$

Department of Medicinal Chemistry, University of Utah, Salt Lake City, UT, 84103, Wyeth Research, Pearl River, NY, 10965

Available Supporting Information

S1. Photo of a Fijian Corticium sp. 
S1. Photo of a Fijian Corticium sp

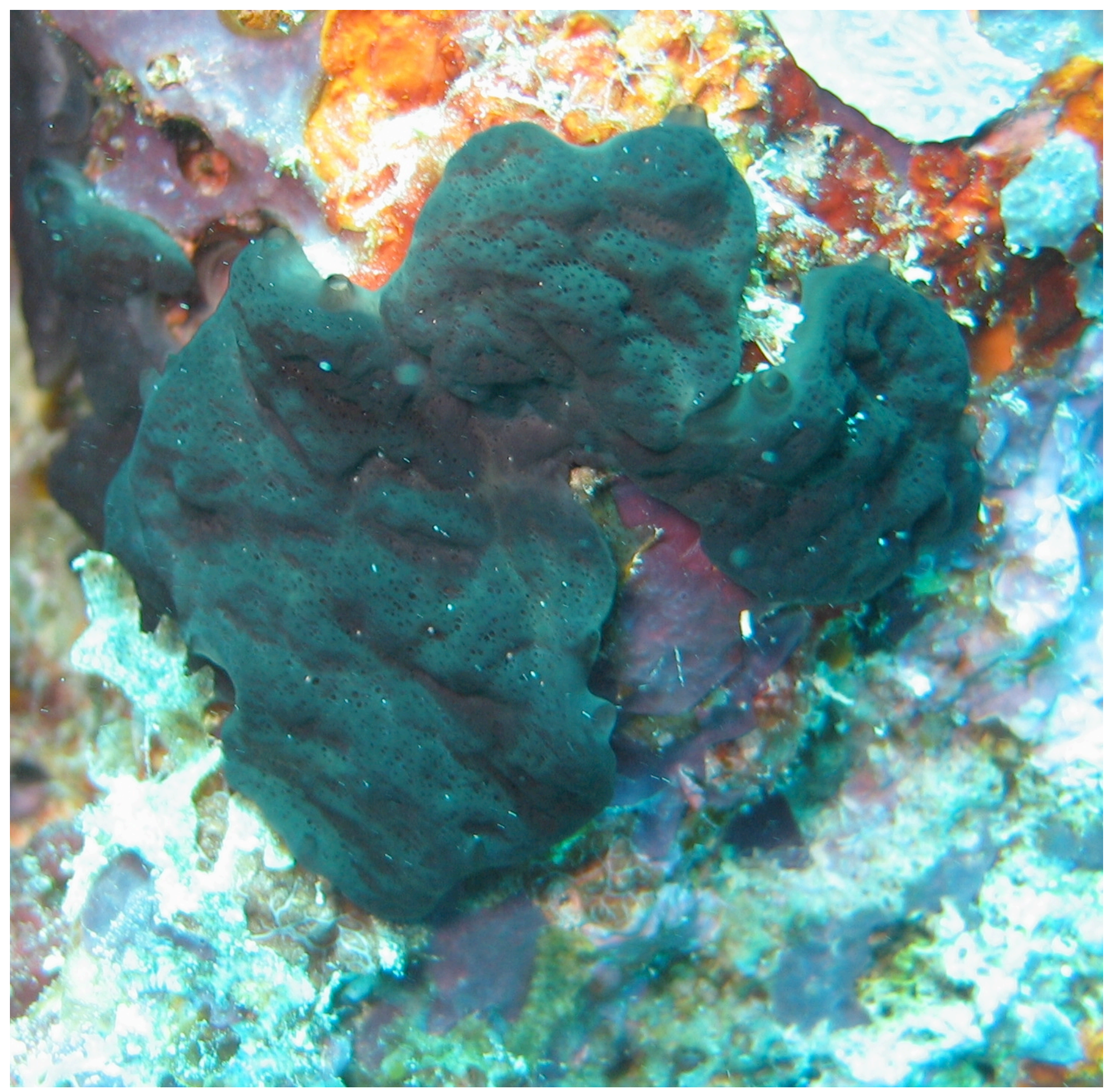

